\title{
PD-L1/PD-1 axis serves an important role in natural killer cell-induced cytotoxicity in osteosarcoma
}

\author{
MING-LEI ZHANG ${ }^{1}$, LI CHEN ${ }^{2}$, YAN-JIAO $\mathrm{LI}^{3}$ and DA-LIANG KONG ${ }^{1}$ \\ ${ }^{1}$ Department of Orthopedics, China-Japan Union Hospital of Jilin University, Changchun, \\ Jilin 130033; ${ }^{2}$ Department of Oral Radiology, School and Hospital of Stomatology, Jilin University; \\ ${ }^{3}$ Department of Pharmacy, The First Hospital of Jilin University, Changchun, Jilin 130021, P.R. China
}

Received January 9, 2019; Accepted July 10, 2019

DOI: $10.3892 / o r .2019 .7299$

\begin{abstract}
Osteosarcoma is a serious malignancy in pediatric patients, which comprises $2.4 \%$ of fatal cancer in children and achieves $20 \%$ of all primary bone cancers. In the present study, we employed three human osteosarcoma cell lines MG-63, HOS and U2OS for susceptibility to cytolytic activity of freshly isolated healthy donor NK cells. Cells were lysed by NK cells in a dose dependent manner. MG-63 cells exhibited less susceptibility to NK cells than HOS and U2OS cells at all cell ratios. The specific mechanism underlying the effects of NK cells on osteosarcoma cells was determined by antibody blockage experiments. The results revealed that granzyme B was the key factor in the NK cell-induced cytotoxicity of human osteosarcoma cells. To the best of our knowledge, the present study is the first to investigate the expression of PD-L1 in MG-63, HOS and U2OS cells. The relative expression of the PD-L1 gene and protein in MG-63 cell was greater than HOS and U2OS cells. The specific lysis of human osteosarcoma cells induced by NK cells was enhanced when PD-L1/PD-1 was blocked by the PD-L1 antibody. The present study proposed that the PD-L1/PD-1 axis serves an important role in NK cell-induced cytotoxicity in osteosarcoma via granzyme B secretion. Our findings may contribute to the development of precise treatments for osteosarcoma based on the expression profile of PD-L1 in patients with this disease.
\end{abstract}

\section{Introduction}

Osteosarcoma (OS) forms $2.4 \%$ of fatal cancer in children. It accounts for $20 \%$ of all primary bone cancers and is a serious malignancy in pediatric patients (1). The 5-year survival rate is only $50-70 \%$ in osteosarcoma patients due to the lack of effective

Correspondence to: Professor Da-Liang Kong, Department of Orthopedics, China-Japan Union Hospital of Jilin University, 126 Xiantai Street, Changchun, Jilin 130033, P.R. China

E-mail: kongdliang@163.com

Key words: programmed death ligand-1, programmed cell death protein 1, natural killer cells, osteosarcoma, granzyme B treatment options currently (2). OS is a primary tumor of bone and was reported to derive from malignant mesenchymal stem cells $(3,4)$. The tumor usually develops in the metaphysis of the long bones; thus, the proximal tibia, the proximal humerus and the distal femur are high risk area of tumor development $(5,6)$. At present, chemotherapy is the first choice of treatments besides surgical treatment. Chemotherapeutic drugs, such as cisplatin, ifosfamide and high-dose methotrexate may result in acquired drug resistance in OS cells (7). Therefore, there is an urgent need for the development of novel effective therapeutic drugs for the treatment of this disease $(8,9)$.

For patients who are not candidates for surgery, immunotherapy is a promising therapeutic option $(9,10)$. Expansion of autologous tumor-specific effector cells ex vivo prior to infusion into the host serves an important role in adoptive cell immunotherapy (11). CIK cells, lymphokine-activated killer cells, tumor-infiltrating lymphocytes, cytotoxic T lymphocyte cells and natural killer (NK) cells are candidate immunological effector cells for treating cancer, or combined targets following surgery $(12,13)$. There have been an increasing number of encouraging clinical results in breast (14), liver (15), and digestive tract (16) cancers by adopting NK cells in treatment. Thus, treating OS via NK cells has drawn increasing attention in the field of cancer immunotherapy. Unlike T cells, NK cells are innate immune lymphocytes, which kill or lyse malignant cells by producing cytokines and chemokines, independent of antigen presentation $(17,18)$. Similar to interleukin (IL)-12, IL-15 and IL-18, IL-17 enhances the susceptibility of U2OS osteosarcoma cells to NK cell lysis (19). NK cell therapy combined with aerosol IL-2 decreased OS lung metastasis tumor burden in a mouse model $(20,21)$; however, the expression of certain inhibitory molecules of tumor cells negatively regulate NK cell function (22).

With the development of immune checkpoint inhibitors for the treatment of malignant tumors, cancer immunotherapy has become an increasingly popular treatment modality in cancer therapy. Programmed death ligand-1 (PD-L1), a popular immune checkpoint, serves an important role in escaping tumor immunosurveillance $(23,24)$. PD-1, a receptor of PD-L1, is expressed on immune cells, including NK cells, and interacts with tumor cells, leading to cell apoptosis, anergy or tolerance (25). A PD-L1 antibody therapy clinical trial (clinical trial no. 2017L04642) was permitted in China after anti-PD-1 antibodies were approved by 
the US FDA for the treatment of melanoma $(26,27)$. In addition, studies have reported that the tumor response to PD-L1 or PD-1 inhibition is directly associated with the expression levels of PD-L1 and lymphocytic infiltration of the tumor (28-30). Previous studies have begun to examine the role of PD-L1 in OS. Utilizing reverse transcription-quantitative polymerase chain reaction (RT-qPCR), PD-L1 mRNA expression was determined to be associated with lymphocyte infiltration (31). PD-L1 blockade in a mouse model of OS revealed the initial regression of the tumor followed by growth of PD-L1 antibody-resistant clones (32). PD-L1 expression was significantly linked to poor 5-year survival rates (33). The present study aimed to investigate the function and mechanism of NK cells on the human OS cells. Whether the difference in the expression ratio of PD-L1 on distinctive OS cell lines result in the different outcomes was also explored. Our findings may suggest the potential of anti-PD-L1 combined with NK cell treatment in high PD-L1 expression-OS cancer.

\section{Materials and methods}

Cell isolation and purification. Peripheral blood mononuclear cells (PBMCs) were freshly isolated from peripheral blood of healthy individuals (three donors were all males, who were 28 years old at March 03, 2018, 24 years old at July 02, 2018 and 31 years old at September 07, 2018) via Ficoll density gradient separation at the speed of $1,174 \mathrm{x}$ g (raising speed at 9 , descent speed at 1) for $30 \mathrm{~min}$ at room temperature. The study was approved by the Ethics Committee of Changchun Blood Center; written informed consent was obtained from all patients. NK cells were enriched through negative selection from outflow cells with an NK cell isolation kit according to the manufacturer's protocols (Miltenyi Biotec). The purity of the purified cells was $\geq 95 \%$ as determined by flow cytometry.

Tumor cell lines. MG-63, HOS and U2OS human OS cell lines, as well as MDA-MB-231 and MCF7 breast cancer cell lines were purchased from the American Type Culture Collection. The MDA-MB-231 breast cancer cell line expresses high levels of PD-L1, whereas that of the MCF7 cell is negligible; thus, these two cells served as the positive and negative controls respectively. The cells were cultured in a 96-well plate containing $200 \mu \mathrm{l}$ complete medium (Dulbecco's modified Eagle's medium), 10\% fetal calf serum, penicillin (100 U/ml), streptomycin $(0.1 \mathrm{mg} / \mathrm{ml})$ and glutamine (Invitrogen; Thermo Fisher Scientific, Inc.) at a density of $5 \times 10^{4}$ cells/well, at $37^{\circ} \mathrm{C}$.

Cellular cytotoxicity assay. NK cell-mediated cellular cytotoxicity was determined using a non-radioactive cellular cytotoxicity assay kit (Techno Suzuta). Tumor cells $\left(5 \times 10^{4}\right)$ in a round bottom 96-well plate were challenged by $100 \mu \mathrm{l}$ of NK cells at effector-to-target ratios of $0: 1,0.2: 1,1.0: 1,5.0: 1$ and 25.0:1 for $40 \mathrm{~min}$ at $37^{\circ} \mathrm{C}$ with $5 \% \mathrm{CO}_{2}$. The detailed procedure was performed as described previously (34).

Flow cytometry. Annexin V-fluorescein isothiocyanate (FITC) and propidium iodide (PI) double staining flow cytometry analyses were employed to assess cell apoptosis. MG-63, HOS and U2OS cells were collected on the experimental endpoint. Cell apoptosis was analyzed using a flow cytometer (FACScan; BD
Biosciences) with FlowJo 7.6 FACS analysis software (FlowJo LLC). The cells in the different portions represented the different cell states as follows: The late-apoptotic cells were present in the upper right portion, the viable cells were present in the lower left portion, and the early apoptotic were cells present in the lower right portion. The rate of apoptosis was obtained from the early apoptotic and the late-apoptotic cells. Brefeldin A (Sigma-Aldrich; Merck KGaA) was subsequently added at a final concentration of $5 \mu \mathrm{g} / \mathrm{ml}$ then further culturing in the $37^{\circ} \mathrm{C}$ incubator for another $4 \mathrm{~h}$. NK cells were stained for surface expression of CD107a, and intracellular expression of granzyme B and interferon (IFN) $-\gamma$. To investigate the involvement of selected molecules, blocking experiments were performed by adding the following monoclonal antibodies (mAbs): $\alpha-P D-L 1$ (cat. no. 9049-B7), $\alpha-$ IFN- $\gamma$ (cat. no. AF-285-SP) and $\alpha$-granzyme B (cat. no. MAB2906-SP). Control experiments were performed using isotype matched mouse antibodies (all mAbs from R\&D Systems). All mAbs were used at a final concentration of $10 \mu \mathrm{g} / \mathrm{ml}$. The antibodies were added to the cell culture plates and incubated at $37^{\circ} \mathrm{C}$ at the beginning of the experiment.

$R T$-qPCR. Total cellular RNA was isolated using TRIzol (Invitrogen; Thermo Fisher Scientific, Inc.). Total RNA was reversed transcribed into cDNA by a reverse transcription kit at $42^{\circ} \mathrm{C}$ for $30 \mathrm{~min}$ and $85^{\circ} \mathrm{C}$ for $5 \mathrm{~min}$ (Beijing Transgen Co., Ltd.). qPCR was conducted using the Fast Start Universal SYBR ${ }^{\circledR}$ Green Master (ROX) kit (Roche Diagnostics). Reactions were performed using $3 \mu \mathrm{l}$ of cDNA in a $20 \mu \mathrm{l}$ reaction volume and the following thermal cycles profile: $10 \mathrm{sec}$ for pre-denaturation at $94^{\circ} \mathrm{C}, 5 \mathrm{sec}$ for denaturation at $94^{\circ} \mathrm{C}$, and $30 \mathrm{sec}$ for extension at $60^{\circ} \mathrm{C}$, for 40 cycles. RT-qPCR was performed using the Power SYBR Green Master Mix (Takara Bio, Inc.) and an ABI 7300 Real-Time PCR system (Applied Biosystems, Thermo Fisher Scientific, Inc.) The primer sequences for PD-L1 were as follows: sense, 5'-TTCCCAGTCCAAACTGAGGAGTCC AAC-3' and antisense, 5'-TTGTTCGCTACCCGAAACGCT GAG-3'. The GAPDH primers were as follows: sense, 5'-CCA GGTGGTCTCCTCTGACTT-3' and antisense, 5'-GTTGCT GTAGCCAAATTCGTTGT-3'.

Western blotting. Cell total protein was extracted using RIPA buffer (Beyotime Institute of Biotechnology) supplemented with a cocktail protease inhibitor (Roche Molecular Diagnostics), and the protein concentration was determined with a BCA kit according to the manufacturer's protocol. A total of 5-40 $\mu \mathrm{g}$ cell total protein was separated by $10 \%$ SDS-PAGE and then were electrotransferred to polyvinylidene fluoride membranes (0.45 $\mu \mathrm{m}$; EMD Millipore) and blocked at $37^{\circ} \mathrm{C}$ for $1 \mathrm{~h}$ with $5 \%$ skim milk in Tris-buffered saline with Tween-20 (0.1\%). Subsequently, membranes were incubated with monoclonal antibodies against PD-L1 (cat. no. 13684, 1:1,000) and $\beta$-actin (cat. no. $3700,1: 1,000$ ) at $4^{\circ} \mathrm{C}$ overnight. The membranes were washed with TBS washing buffer six times, and then incubated with horseradish peroxidase-conjugated goat anti-mouse (cat. no. TA130001) or goat anti-rabbit (cat. no. TA130015) secondary antibodies $\left(1: 2,000\right.$; OriGene Technologies, Inc.) at $37^{\circ} \mathrm{C}$ for $1 \mathrm{~h}$. The detailed procedure was performed as described previously (33). Protein expression levels were determined semi-quantitatively by densitometric analysis with the Quantity One software (V4.62, Bio-Rad Laboratories, Inc.). 


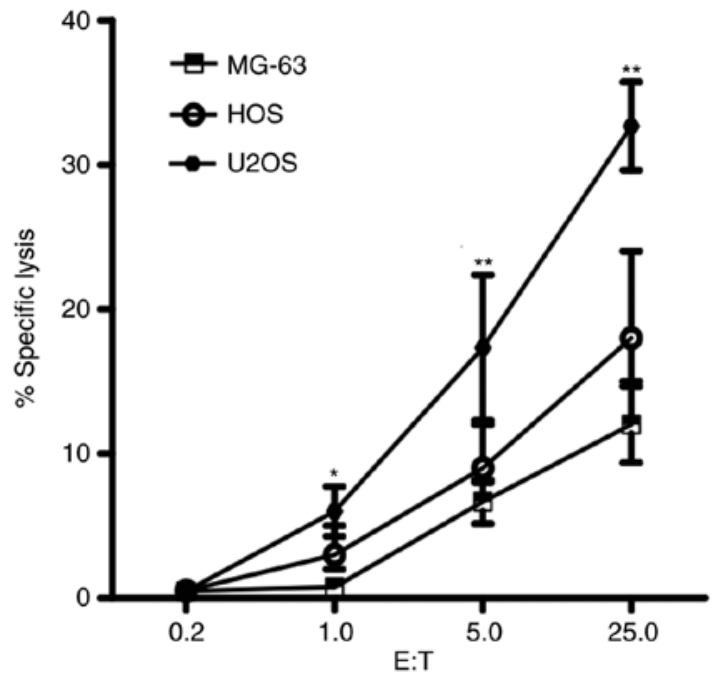

Figure 1. Three human osteosarcoma cell lines possess distinct susceptibilities to NK cells. MG-63, HOS and U2OS cells were plated in a 96-well plate $24 \mathrm{~h}$ before NK cells were added. E:T ratios were 0:1, 0.2:1, 1.0:1, 5.0:1 and 25.0:1. NK cell-mediated cellular cytotoxicity was determined using a nonradioactive cellular cytotoxicity assay kit. The data are expressed as the mean \pm standard deviation of three experiments. ${ }^{*} \mathrm{P}<0.05$ and ${ }^{* *} \mathrm{P}<0.01$ vs. control. E:T, effector-to-target; NK cells, natural killer cells.

Enzyme-linked immunosorbent assay (ELISA). The supernatants of the cell cultures were collected in each experimental condition. Granzyme B (cat. no. DY2906-05, R\&D Systems) and IFN- $\gamma$ (cat. no. DIF50, R\&D Systems) concentrations were measured by ELISA according to the manufacturer's instructions.

Statistical analysis. All data and results were calculated from at least three replicate measurements and are presented as the mean \pm standard deviation. Mean values were compared using one-way ANOVA multiple comparison tests. $\mathrm{P}<0.05$ was considered to indicate a statistically significant difference. All statistical tests were performed with GraphPad Prism software (v5.0, GraphPad Software, Inc.).

\section{Results}

Three human osteosarcoma cell lines with distinctive susceptibility to NK cells. We tested 3 human osteosarcoma cell lines MG-63, HOS and U2OS, for susceptibility to cytolytic activity of freshly isolated healthy donor NK cells. All cell lines were lysed by NK cells in a dose dependent manner (1.0:1, 5.0:1 and 25.0:1). U2OS cells exhibited significantly increased susceptibility to NK cells compared with MG-63 and HOS cells at all ratios $(\mathrm{P}<0.05$; Fig. 1$)$. The susceptibility to the cytolytic activity of NK cells in MG-63 cells was reduced compared with the other two cell lines. HOS cells exhibited moderate cytolysis. The results indicate that different human osteosarcoma cell lines have distinct susceptibilities to NK cells.

Flow cytometry analysis of human OS cell apoptosis. Annexin V-FITC and PI double-staining flow cytometry analyses were performed. The MG-63, HOS and U2OS cells were plated in 96-well plates containing $200 \mu \mathrm{l}$ medium at a density of $5 \times 10^{4}$ cells/well. The induction of apoptosis was examined with or without NK cells (effector-to-target ratio $=20: 1$ ). As presented in Fig. 2, the number of early- and late-apoptotic cells increased significantly in the NK cell-treated groups compared with that in the control group. The apoptotic effects of NK cells on U2OS cells $(29.3 \pm 3.2 \%$ vs. $1.5 \pm 0.45 \%, \mathrm{P}<0.01)$ and HOS $(16.3 \pm 2.2 \%$ vs. $1.6 \pm 0.68 \%, \mathrm{P}<0.05)$ cells were significantly increased compared with the corresponding control cells. Similar to the cellular cytotoxicity assay results, MG-63 cells exhibited a reduced apoptosis rate than that of U2OS and HOS cells $(\mathrm{P}<0.05)$.

NK cells lyse human OS cells in a granzyme B-dependent manner. CD107a, a cytotoxicity marker, was determined to be upregulated in NK cells when cocultured with the human OS cells in the present study. As shown in Fig. 3A and B, $28.9 \pm 1.3(\mathrm{P}<0.01)$ and $12.3 \pm 2.1 \%(\mathrm{P}<0.05) \mathrm{CD} 107 \mathrm{a}^{+} \mathrm{NK}$ cells were counted upon coculturing with U2OS and HOS cells, respectively. Upon culture with MG-63 cells, fewer CD107a ${ }^{+}$ $\mathrm{NK}$ cells were detected when compared with U2OS $(8.2 \pm 1.5 \%$ vs. $28.9 \pm 1.3 \%, \mathrm{P}<0.01)$ and HOS cells $(8.2 \pm 1.5 \%$ vs. $12.3 \pm 2.1 \%$, $\mathrm{P}<0.01)$. Granzyme B and IFN- $\gamma$ concentrations in the cell culture supernatant were measured by ELISA. As shown in Fig. 3C and D, consistent with CD107a expression, granzyme B and IFN- $\gamma$ secretion levels were elevated in response to $\mathrm{NK}$ and OD coculturing. Unlike granzyme B and CD107a, IFN- $\gamma$ secretion in all three human OS cells was comparable $(\mathrm{P}>0.05)$. To determine whether granzyme B may be the key factor in the cytotoxic effects of NK cells on human OS cells, granzyme B and IFN- $\gamma$ antibodies were added to the NK cell/human OS cell coculture systems. As presented in Fig. 4A, the cytolytic activity of NK cells on MG-63, HOS and U2OS cells was significantly reduced when granzyme $\mathrm{B}$ was blocked compared with the control $(\mathrm{P}<0.05)$. In contrast, when the IFN- $\gamma$ antibody was added, no differences in the cytolytic activity of NK cells on human OS cells were observed $(\mathrm{P}>0.05)$. The detection of cell apoptosis by FACS revealed supporting findings in which the inhibition of granzyme B led to the significant reduction in apoptosis compared with the control; significant differences were not observed between the IFN- $\gamma$-inhibited and control groups (Fig. 4B). These results suggested that NK cells lyse human OS cells in a granzyme B-dependent manner.

Expression of PD-L1 in MG-63 cell is greater than that of U2OS and HOS cells. Tumor cells express PD-L1 to inhibit NK cell cytolytic activity as NK cells express PD-1 (22). In the present study, the expression of PD-L1 on MG-63, HOS and U2OS cells was investigated. PD-L1 expression was quantified by RT-qPCR and western blotting. The relative expression of the PD-L1 in MG-63 cell was significantly greater than that in the HOS and U2OS cells $(\mathrm{P}<0.01$; Fig. 5A). Western blotting revealed that the protein expression of PD-L1 in MG-63 cells was $~ 3-5$ folds greater than that in HOS and U2OS cells $(\mathrm{P}<0.05$; Fig. 5B and $\mathrm{C})$.

PD-L1 blockage enhances the cytotoxicity of NK cells in human OS cells. To investigate the pivotal role of PD-L1/PD-1 checkpoint on the cytotoxicity of NK cells in human OS cells, PD-L1 antibody was added to the NK cell/human OS cell coculture systems. The specific lysis induced by NK cells of human OS cells was significantly enhanced when PD-L1/PD-1 blocked by PD-L1 antibody, compared with the control $(\mathrm{P}<0.05$; Fig. 6A). Interestingly, the fold-change in the specific lysis of 

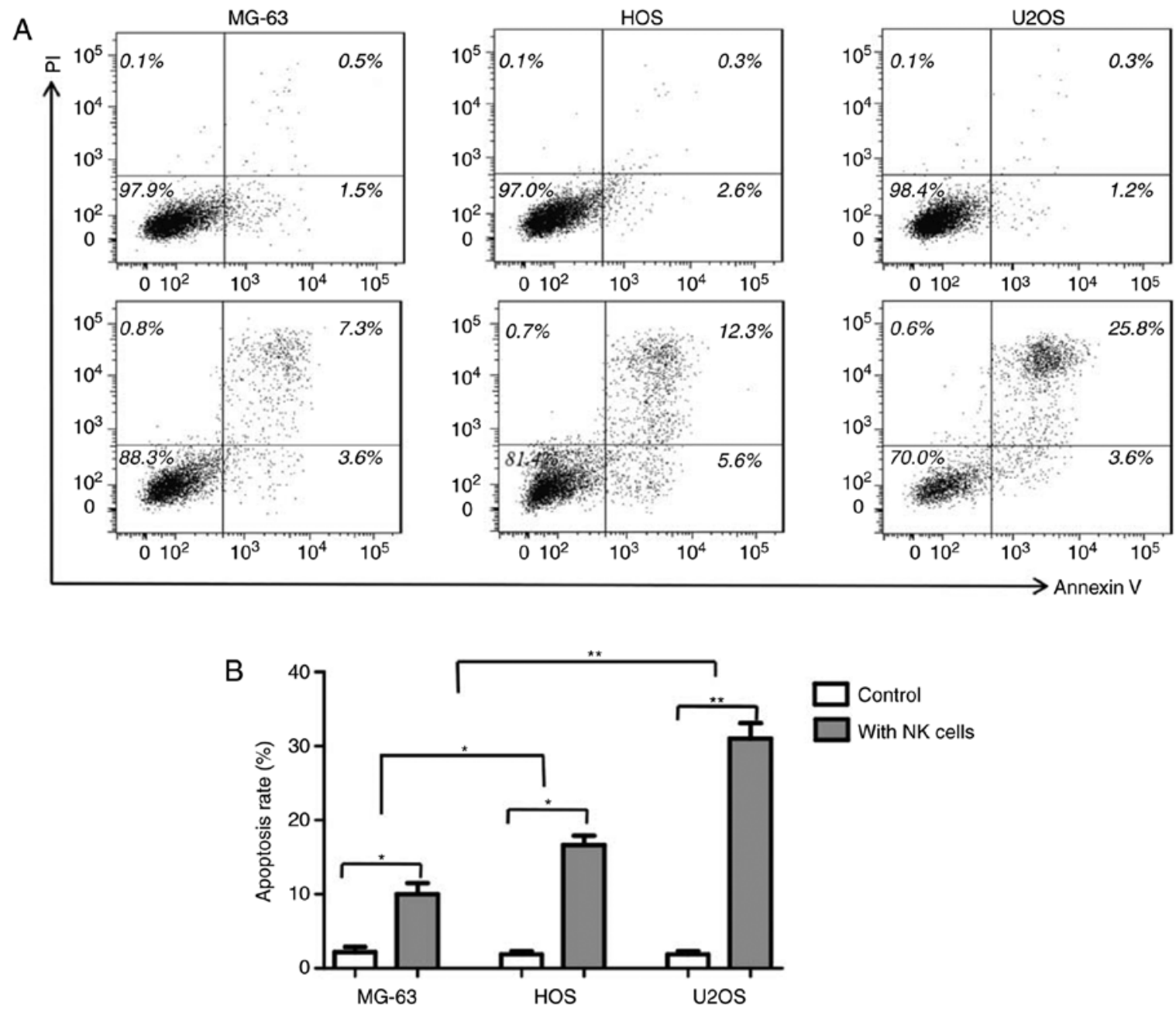

Figure 2. Detection of apoptosis by flow cytometry in human osteosarcoma cells treated with NK cells. Flow cytometric analysis of apoptosis in MG-63, HOS and U2OS cells treated with NK cells at an effector-to-target ratio $=20: 1$. Tumor cells cultured alone were used as the control. (A) Representative figure of flow cytometric analysis of human osteosarcoma cell apoptosis. (B) Statistical analysis of the percentage of apoptotic cells in three independent arrays. The data are expressed as the mean \pm standard deviation of three experiments. ${ }^{*} \mathrm{P}<0.05$ and ${ }^{* *} \mathrm{P}<0.01$. NK cells, natural killer cells; PI, propidium iodide.
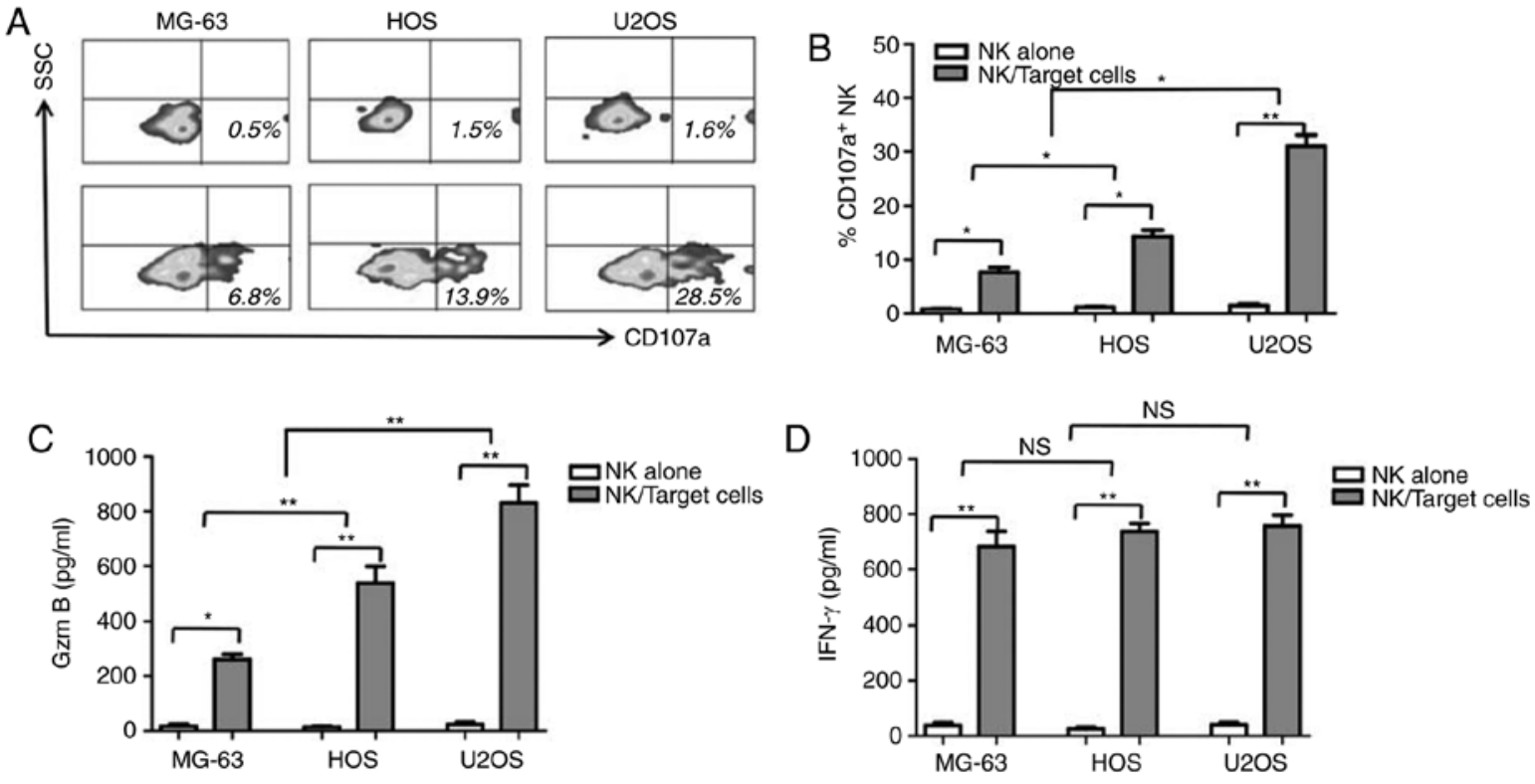

Figure 3. Detection of the cytotoxic effects of NK cells on human osteosarcoma cells. NK cells were stained for the surface expression of CD107a and the intracellular expression of granzyme B and IFN- $\gamma$ after coculture with MG-63, HOS and U2OS cells. (A and B) CD107a ${ }^{+}$NK cell percentage. (C) GzmB and (D) IFN- $\gamma$ concentrations in the cell culture supernatant were measured by ELISA. The data are expressed as the mean \pm standard deviation of three experiments. NS, no significance, $\mathrm{P}>0.05$. ${ }^{*} \mathrm{P}<0.05$ and ${ }^{* *} \mathrm{P}<0.01$. Gzm B, granzyme B; IFN- $\gamma$, interferon- $\gamma ; \mathrm{NK}$ cells, natural killer cells. 

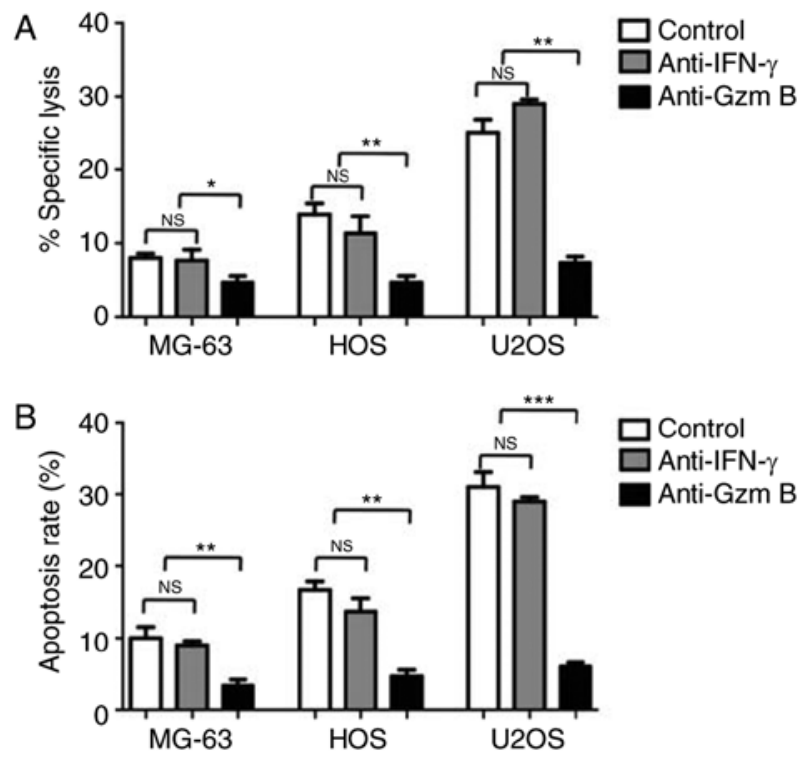

Figure 4. NK cells lyse human osteosarcoma cells in a granzyme B-dependent manner. Granzyme B and IFN- $\gamma$ antibodies were added to the NK cell/human osteosarcoma cell coculture system. MG-63, HOS and U2OS cells were treated with NK cells at effector-to-target ratio $=20: 1$. (A) NK cell-mediated cellular cytotoxicity was determined using a nonradioactive cellular cytotoxicity assay kit. (B) Flow cytometric analysis of apoptosis in MG-63, HOS and U2OS cells. The data are expressed as the mean \pm standard deviation of three experiments. NS, no significance, $\mathrm{P}>0.05 .{ }^{*} \mathrm{P}<0.05,{ }^{* *} \mathrm{P}<0.01$ and ${ }^{* * * *} \mathrm{P}<0.001$. IFN $-\gamma$, interferon- $\gamma$; NK cells, natural killer cells.

MG-63 cells was significantly increased than that of HOS and U2OS cells $(\mathrm{P}<0.01$; Fig. 6B). This may be due to the notably upregulated expression of PD-L1 MG-63 cells than in the other two cell lines. CD107a expression $(\mathrm{P}<0.05$; Fig. $6 \mathrm{C})$ secretion of NK cells was also enhanced with the coculture with all three cell lines; significant increases in granzyme B secretion was observed in MG-63 and HOS cells compared with the control $(\mathrm{P}<0.05$; Fig. 6D). On the contrary, IFN- $\gamma$ secretion from NK cells in all coculture systems did not significantly change in the presence or absence of PD-L1 antibody ( $\mathrm{P}>0.05$; Fig. $6 \mathrm{E})$.

These results indicated that PD-L1 expression in human OS cell lines plays an important role in the susceptibility to NK cells. The PD-L1/PD-1 interaction was proposed to serve an important role in the evasion of tumor immunosurveillance (Fig. 7).

\section{Discussion}

The association between the host immune system, the type of cancer and cancer treatment applied is extremely complex $(29,30)$. Immunotherapies that include PD-1/PD-L1 blockade have shown prolonged clinical activity against various human malignancies excluding OS (31), despite the fact that there is evidence that PD-L1 contributes to OS progression in animal experiments (32). As the main components of the innate immune system, NK cells can kill tumor cells or infected cells directly, independent of antigen presenting cells. CD56 $6^{\text {dim }} \mathrm{CD} 16^{\text {bright }} \mathrm{NK}$ cells $(\sim 90 \%)$ and $\mathrm{CD} 56^{\text {bright }} \mathrm{CD} 16^{\text {dim }}$ NK cells $(\sim 10 \%)$ are two subsets of NK cells in healthy adult peripheral blood (35). CD56 ${ }^{\mathrm{dim}} \mathrm{CD} 16^{\text {bright }} \mathrm{NK}$ cells exert mainly cytolytic functions by secreting granzyme B and perforin,
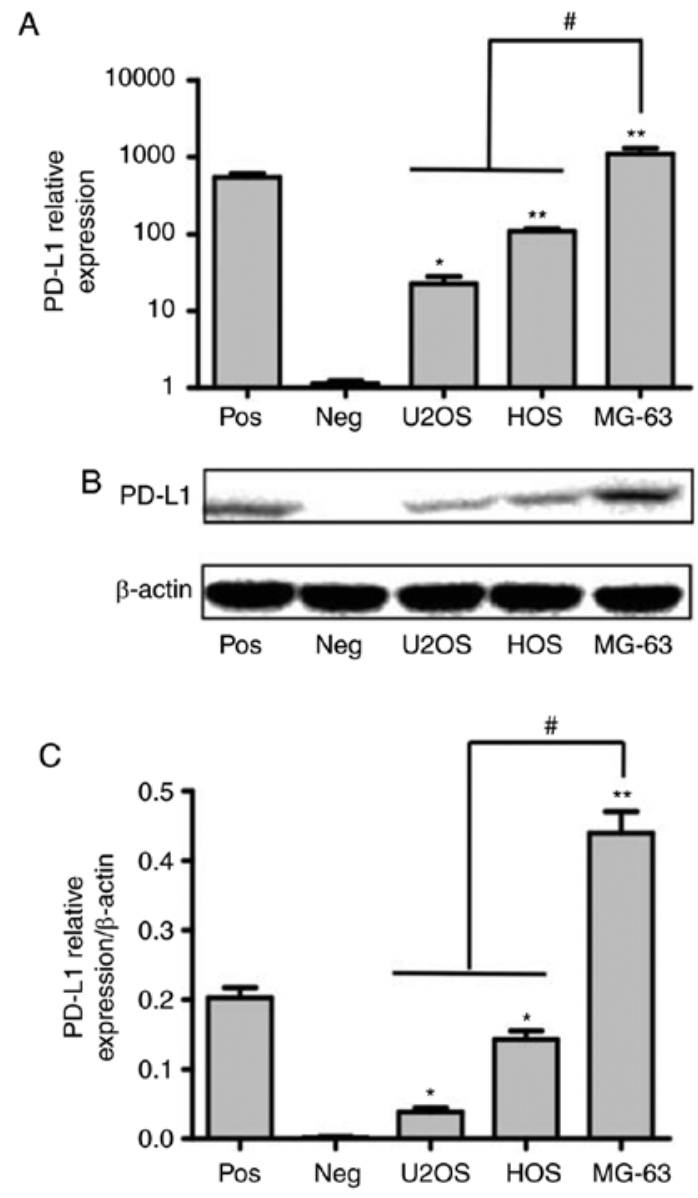

Figure 5.Expression of PD-L1 in MG-63,HOS and U2OS cells.PD-L1 expression in MG-63, HOS and U2OS cells was quantified by reverse transcription-quantitative polymerase chain reaction and western blotting. The MDA-MB-231 breast cancer cell line expresses a high level of PD-L1 and served as the positive control. The MCF7 breast cancer cell line does not express PD-L1 and served as the negative control. (A) The relative mRNA expression of PD-L1 in MG-63, HOS and U2OS cells. (B and C) Protein expression in MG-63, HOS and U2OS cells. The data are expressed as the mean \pm standard deviation of three experiments. ${ }^{~} \mathrm{P}<0.05$ and ${ }^{* *} \mathrm{P}<0.01$ vs. negative control. ${ }^{.} \mathrm{P}<0.05$. PD-L1, programmed death ligand-1; Neg, negative; Pos, positive.

whereas $\mathrm{CD} 56^{\text {bright }} \mathrm{CD} 16^{\mathrm{dim}} \mathrm{NK}$ cells exert primarily immune regulatory functions by secreting cytokines (33). Cells lacking major histocompatibility (MHC) molecules can activate NK cells by interacting with activating receptors on the cell surface, including NKp30, NKp40, NKG2D and NKp46 (36). Tumor cells are more susceptible to NK cells due to the lack of MHC class-I molecules (34). In this study, we tested three human OS cell lines MG-63, HOS and U2OS for susceptibility to cytolytic activity of freshly isolated healthy donor NK cells. All cell lines were lysed by NK cells in a dose-dependent manner. MG-63 cells exhibited reduced susceptibility to NK cells than HOS and U2OS cells at all ratios. This finding indicated that human OS cells, similar to the other malignant cells, such as non-small cell lung cancer and melanoma cells, are more susceptible to NK cells; however, variations in the expression of certain inhibitory molecules in different cell lines and patients may account for differences in analysis.

PD-L1, a systemic immune checkpoint, plays an important role in escaping tumor immunosurveillance. PD-1, as a receptor of PD-L1, is expressed on immune cells including NK cells, and 

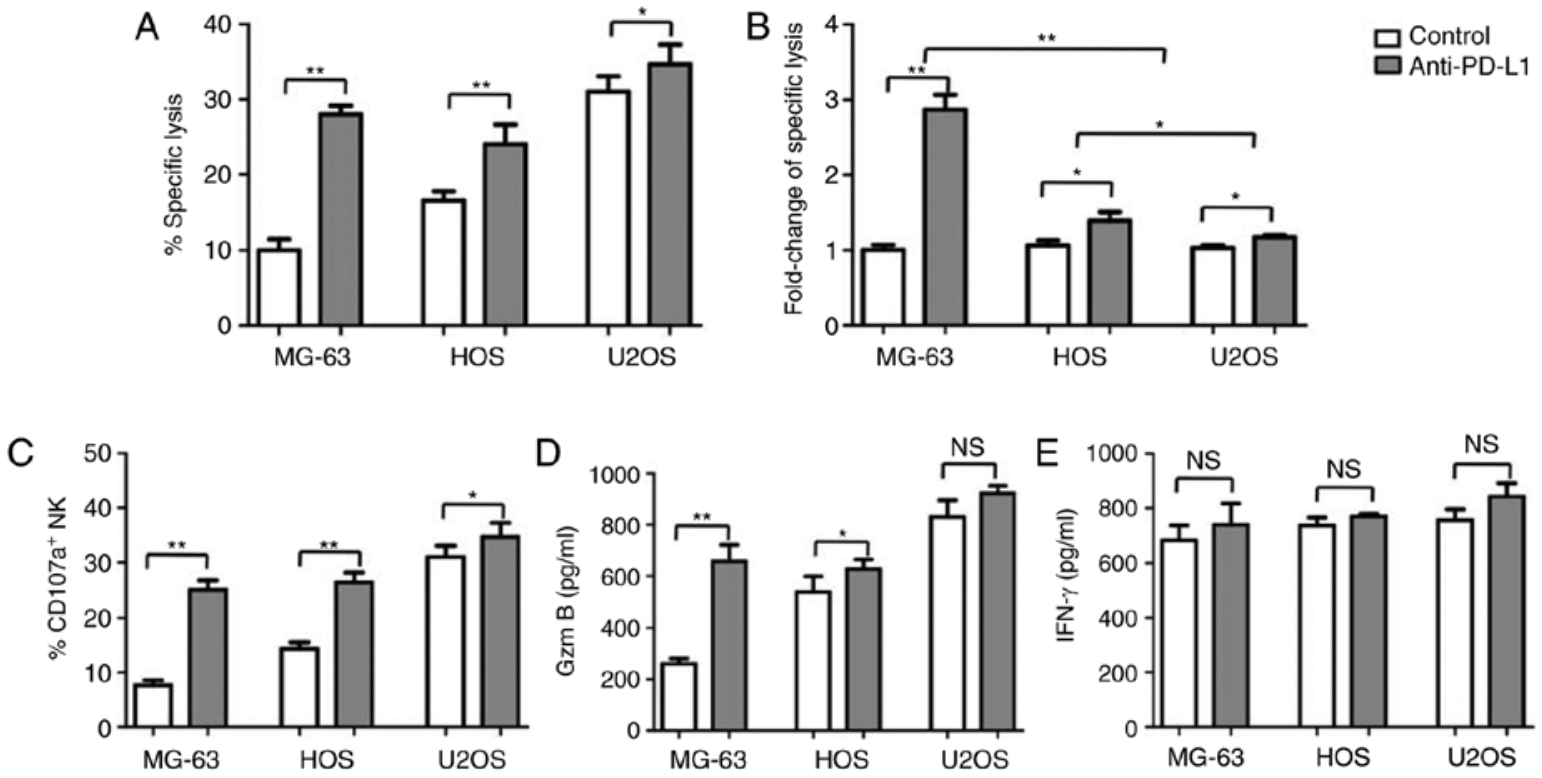

Figure 6. PD-L1 blockage enhanced the cytotoxicity of NK cells in human osteosarcoma cells. PD-L1 antibody was added to the NK cell/human osteosarcoma cell coculture system. (A) NK cell-mediated cellular cytotoxicity in MG-63, HOS and U2OS cells. (B) The fold-change of specific lysis in human osteosarcoma cells in the presence or absence of PD-L1 antibody. (C) CD107a ${ }^{+}$NK cell percentage. (D) Gzm B and (E) IFN- $\gamma$ concentrations in the cell culture supernatant. The data are expressed as the mean \pm the standard deviation of three experiments. NS, no significance, $\mathrm{P}>0.05$. ${ }^{*} \mathrm{P}<0.05$ and ${ }^{* *} \mathrm{P}<0.01$. Gzm $\mathrm{B}$, granzyme $\mathrm{B}$; IFN- $\gamma$, interferon- $\gamma$; NK cells, natural killer cells; PD-L1, programmed death ligand-1.

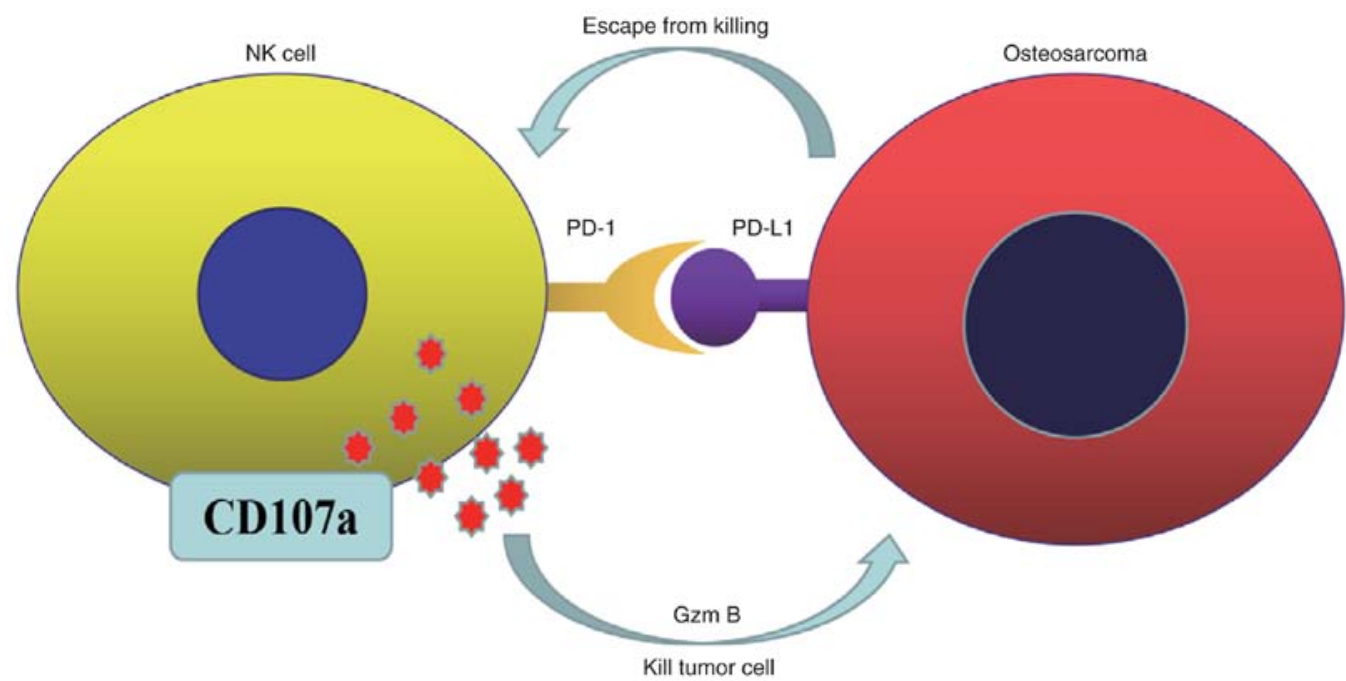

Figure 7. Schematic outline of the PD-L1/PD-1 axis on the cytotoxicity of natural killer cells in human osteosarcoma cells by Gzm B secretion. NK cells kill human osteosarcoma cells that lack major histocompatibility molecules by exerting cytolytic functions, mainly by secreting Gzm B and expressing CD107a; however, certain human osteosarcoma cell lines or patients with osteosarcoma that overexpress PD-L1 molecules demonstrate an interaction between PD-L1 and PD-1 on NK cells so that the cells can evade immunosurveillance. Gzm B, granzyme B; NK cells, natural killer cells; PD-1, programmed cell death protein 1; PD-L1, programmed death ligand-1.

interacts with tumor cells, leading to cell apoptosis, anergy or tolerance. PD-L1 expression appears to be conserved across a number of solid tumors and hematologic malignancies (37). The PD-L1 protein is expressed in a variety of cancers, such as melanoma, non-small cell lung cancer, lymphomas and osteosarcoma (38). The detection of PD-L1 protein expression by IHC in the tumors of patients is a predictor of responses to both anti-PD-L1 and anti-PD-1 therapy in a variety of cancers $(29,30)$. The relative gene and protein expression levels of PD-L1 in MG-63 cell was greater than those in HOS and U2OS cells. PD-L1 antibody was added to the NK cell/human
OS cell coculture system. The specific lysis of NK cells in human OS cells was enhanced when PD-L1/PD-1 was blocked by the PD-L1 antibody.

To further address the specific mechanism of NK cells in human OS cells, CD107a, granzyme B and IFN- $\gamma$ secretion was detected. When cocultured with human OS cells, CD107a was significantly expressed. Granzyme B may be the key factor of NK cell-induced cytotoxicity of human OS cells. To prove this hypothesis, granzyme B and IFN- $\gamma$ antibodies were added to the NK cell/human OS cell coculture system. The cytolytic activity of NK cells in human OS cells was moderated when granzyme 
B was blocked. On the contrary, in the presence or absence of IFN- $\gamma$ antibody, no difference in the cytolytic activity of NK cells on human OS cells was observed. These results suggested that NK cells lyse human OS cells in a granzyme B-dependent manner.

For patients who are not candidates for surgery, immunotherapy could be a promising therapeutic option for treating those with advanced cancer (39). The expansion of the autologous tumor-specific effector cells ex vivo prior to infusion into the host serves an important role in adoptive cell immunotherapy (40). The clinical success of cancer immunotherapies targeting T-cell immune checkpoint receptors PD-1/PD-L1 has demonstrated the importance of immunoevasion as a hallmark of cancer (41). Similar to T cells, NK cell also can kill tumor cells directly after PD-1/PD-L1 blockage (42). Increased expression of PD-1 on NK cells prevents NK cell-mediated anti-tumor function via the secretion of granzyme B and is correlated with poor prognosis in digestive cancers (43). It has been well documented that lactate in the tumor microenvironment induces immunosuppression, which results in NK cell apoptosis and reduces the frequency of cell infiltration into these tumors (44). NK cells are potential effector cells against cancer, including blood malignancies and solid tumors, such as such as non-small cell lung cancer, melanoma. The numbers of tumor-infiltrating NK cells was positively correlated with the outcome (45). Lower NK cell activity in the body has been associated with an increased risk of cancer development (46). The immunological characteristics of cancer cells are also important indicators of the choice of therapy. Although the our findings indicated that the PD-L1/PD-1 axis regulates granzyme B secretion, the mechanism requires further investigation. Our future work will involve investigation into the underlying mechanisms. In summary, the present study revealed that the PD-L1/PD-1 axis serves an important role in the NK cell cytotoxicity in OS via granzyme B secretion. The decision of whether or not to use anti-PD-L1 and anti-PD-1 therapy depends on the detection of the protein expression of PD-L1 by IHC in the tumors of patients. Our findings may contribute to development of the precise treatment of human OS.

\section{Acknowledgements}

Not applicable.

\section{Funding}

Not applicable.

\section{Availability of data and materials}

All data generated or analyzed during this study are included in this published article.

\section{Authors' contributions}

MLZ, LC and YJL planned and performed the experiments, and analyzed the data. DLK made substantial contributions to the design of the present study, interpreted the data and obtained funding, and wrote the manuscript. All authors read and approved the final version of the manuscript.

\section{Ethics approval and consent to participate}

The study was approved by the Ethics Committee of Changchun Blood Center; written informed consent was obtained from all patients.

\section{Patient consent for publication}

Not applicable.

\section{Competing interests}

The authors declare that they have no competing interests.

\section{References}

1. Bielack SS, Kempf-Bielack B, Delling G, Exner GU, Flege S, Helmke K, Kotz R, Salzer-Kuntschik M, Werner M, Winkelmann W, et al: Prognostic factors in high-grade osteosarcoma of the extremities or trunk: An analysis of 1,702 patients treated on neoadjuvant cooperative osteosarcoma study group protocols. J Clin Oncol 20: 776-790, 2002.

2. Torres K and Horwitz SB: Mechanisms of Taxol-induced cell death are concentration dependent. Cancer Res 58: 3620-3626, 1998.

3. Anderson ME: Update on survival in osteosarcoma. Orthop Clin North Am 47: 283-292, 2016.

4. Ferrari S and Serra M: An update on chemotherapy for osteosarcoma. Expert Opin Pharmacother 16: 2727-2736, 2015.

5. Jaffe N: Osteosarcoma: Review of the past, impact on the future. The American experience. Cancer Treat Res 152: 239-262, 2009.

6. Gai P, Sun H, Wang G, Xu Q, Qi X, Zhang Z and Jiang L: miR-22 promotes apoptosis of osteosarcoma cells via inducing cell cycle arrest. Oncol Lett 13: 2354-2358, 2017.

7. Zhao B, Wei X, Li W, Udan RS, Yang Q, Kim J, Xie J, Ikenoue T, $\mathrm{Yu} \mathrm{J}, \mathrm{Li} \mathrm{L}$, et al: Inactivation of YAP oncoprotein by the Hippo pathway is involved in cell contact inhibition and tissue growth control. Genes Dev 21: 2747-2761, 2007.

8. Steinhardt AA, Gayyed MF, Klein AP, Dong J, Maitra A, Pan D, Montgomery EA and Anders RA: Expression of Yes-associated protein in common solid tumors. Hum Pathol 39: 1582-1589, 2008.

9. Yin J, Dong Q, Zheng M, Xu X, Zou G, Ma G and Li K: Antitumor activity of dobutamine on human osteosarcoma cells. Oncol Lett 11: 3676-3680, 2016.

10. Kubo M, Morisaki T, Kuroki H, Tasaki A, Yamanaka N, Matsumoto K, Nakamura K, Onishi H, Baba E and Katano M: Combination of adoptive immunotherapy with Herceptin for patients with HER2-expressing breast cancer. Anticancer Res 23: 4443-4449, 2003.

11. Wu C, Jiang J, Shi $\mathrm{L}$ and $\mathrm{Xu}$ N: Prospective study of chemotherapy in combination with cytokine-induced killer cells in patients suffering from advanced non-small cell lung cancer. Anticancer Res 28: 3997-4002, 2008.

12. Choi D, Kim TG and Sung YC: The past, present, and future of adoptive T cell therapy. Immune Netw 12: 139-147, 2012.

13. Sangiolo D: Cytokine induced killer cells as promising immunotherapy for solid tumors. J Cancer 2: 363-368, 2011.

14. Geller MA, Cooley S, Judson PL, Ghebre R, Carson LF, Argenta PA, Jonson AL, Panoskaltsis-Mortari A, Curtsinger J, McKenna D, et al: A phase II study of allogeneic natural killer cell therapy to treat patients with recurrent ovarian and breast cancer. Cytotherapy 13: 98-107, 2011.

15. Sun C, Sun HY, Xiao WH, Zhang C and Tian ZG: Natural killer cell dysfunction in hepatocellular carcinoma and NK cell-based immunotherapy. Acta Pharmacol Sin 36: 1191-1199, 2015.

16. Sakamoto N, Ishikawa T, Kokura S, Okayama T, Oka K, Ideno M, Sakai F, Kato A, Tanabe M, Enoki T, et al: Phase I clinical trial of autologous NK cell therapy using novel expansion method in patients with advanced digestive cancer. J Transl Med 13: 277, 2015.

17. Zhao Y,Hu J, Li R, Song J, Kang Y, Liu S and Zhang D: Enhanced NK cell adoptive antitumor effects against breast cancer in vitro via blockade of the transforming growth factor- $\beta$ signaling pathway. Onco Targets Ther 8: 1553-1559, 2015. 
18. Cheng M, Chen Y, Xiao W, Sun R and Tian Z: NK cell-based immunotherapy for malignant diseases. Cell Mol Immunol 10: 230-252, 2013.

19. Honorati MC, Neri S, Cattini L and Facchini A: IL-17 enhances the susceptibility of U-2 OS osteosarcoma cells to NK cell lysis. Clin Exp Immunol 133: 344-349, 2003.

20. Guma SR, Lee DA, Ling Y, Gordon N and Kleinerman ES: Aerosol interleukin-2 induces natural killer cell proliferation in the lung and combination therapy improves the survival of mice with osteosarcoma lung metastasis. Pediatr Blood Cancer 61: 1362-1368, 2014

21. Kiany S, Huang G and Kleinerman ES: Effect of entinostat on NK cell-mediated cytotoxicity against osteosarcoma cells and osteosarcoma lung metastasis. Oncoimmunology 6: e1333214, 2017.

22. Makowska A, Braunschweig T, Denecke B, Shen L, Baloche V, Busson $P$ and Kontny U: Interferon $\beta$ and anti-PD-1/PD-L1 checkpoint blockade cooperate in nk cell-mediated killing of nasopharyngeal carcinoma cells. Transl Oncol 12: 1237-1256, Jul 8, 2019 (Epub ahead of print).

23. Carreno BM and Collins M: The B7 family of ligands and its receptors: New pathways for costimulation and inhibition of immune responses. Annu Rev Immunol 20: 29-53, 2002.

24. Dong $\mathrm{H}$ and Chen L: B7-H1 pathway and its role in the evasion of tumor immunity. J Mol Med (Berl) 81: 281-287, 2003.

25. Pesce S, Greppi M, Grossi F, Del Zotto G, Moretta L, Sivori S, Genova C and Marcenaro E: PD/1-PD-Ls checkpoint: Insight on the potential role of NK cells. Front Immunol 10: 1242, 2019

26. McDermott DF and Atkins MB: PD-1 as a potential target in cancer therapy. Cancer Med 2: 662-673, 2013.

27. Swaika A, Hammond WA and Joseph RW: Current state of antiPD-L1 and anti-PD-1 agents in cancer therapy. Mol Immunol 67: 4-17, 2015.

28. Chen BJ, Chapuy B, Ouyang J, Sun HH, Roemer MG, Xu ML, Yu H, Fletcher CD, Freeman GJ, Shipp MA and Rodig SJ: PD-L1 expression is characteristic of a subset of aggressive B-cell lymphomas and virus-associated malignancies. Clin Cancer Res 19: 3462-3473, 2013.

29. Herbst RS, Soria JC, Kowanetz M, Fine GD, Hamid O, Gordon MS, Sosman JA, McDermott DF, Powderly JD, Gettinger SN, et al: Predictive correlates of response to the anti-PD-L1 antibody MPDL3280A in cancer patients. Nature 515: 563-567, 2014.

30. Wimberly H, Brown JR, Schalper K, Haack H, Silver MR, Nixon C, Bossuyt V, Pusztai L, Lannin DR and Rimm DL: PD-L1 expression correlates with tumor-infltrating lymphocytes and response to neoadjuvant chemotherapy in breast cancer. Cancer Immunol Res 3: 326-332, 2015.

31. Lussier DM, Johnson JL, Hingorani P and Blattman JN: Combination immunotherapy with $\alpha$-CTLA- $4 \alpha$-PD-L1 antibody blockade and prevent immuneescape and leads to complete control of metastatic osteosarcoma. J Immunother Cancer 3: 21, 2015.

32. Markel JE, Noore J, Emery EJ, Bobnar HJ, Kleinerman ES and Lindsey BA: Using the Spleen as an in vivo systemic immune barometer alongside osteosarcoma disease progression and Immunotherapy with $\alpha$-PD-L1. Sarcoma 2018: 8694397, 2018.
33. Koirala P, Roth ME, Gill J, Piperdi S, Chinai JM, Geller DS, Hoang BH, Park A, Fremed MA, Zang X and Gorlick R: Immune infiltration and PD-L1 expression in the tumor microenvironment are prognostic in osteosarcoma. Sci Rep 6: 30093, 2016.

34. Senju H, Kumagai A, Nakamura Y, Yamaguchi H, Nakatomi K, Fukami S, Shiraishi K, Harada Y, Nakamura M, Okamura H, et al: Effect of IL-18 on the expansion and phenotype of human natural killer cells: Application to cancer immunotherapy. Int J Biol Sci 14: 331-340, 2018.

35. Li H, Zhai N, Wang Z, Song H, Yang Y, Cui A, Li T, Wang G, Niu J, Crispe IN, et al: Regulatory NK cells mediated between immunosuppressive monocytes and dysfunctional $\mathrm{T}$ cells in chronic HBV infection. Gut 67: 2035-2044, 2018.

36. Choi YH, Lim EJ, Kim SW, Moon YW, Park KS and An HJ: IL-27 enhances IL-15/IL-18-mediated activation of human natural killer cells. J Immunother Cancer 7: 168, 2019.

37. Feng M, Xiong G, Cao Z, Yang G, Zheng S, Song X, You L, Zheng L, Zhang T and Zhao Y: PD-1/PD-L1 and immunotherapy for pancreatic cancer. Cancer Lett 407: 57-65, 2017.

38. Wang ZF, Sun WY, Yu DH, Zhao Y, Xu HM, He YF and Li HJ: Rotundic acid enhances the impact of radiological toxicity on MCF-7 cells through the ATM/p53 pathway. Int J Oncol 53: 2269-2277, 2018

39. Von Pawel J, Bordoni R, Satouchi M, Fehrenbacher L, Cobo M, Han JY, Hida T, Moro-Sibilot D, Conkling P, Gandara DR, et al: Long-term survival in patients with advanced non-small-cell lung cancer treated with atezolizumab versus docetaxel: Results from the randomised phase III OAK study. Eur J Cancer 107: 124-132, 2019.

40. Corgnac S, Boutet M, Kfoury M, Naltet C and Mami-Chouaib F: The emerging role of $\mathrm{CD}^{+}$tissue resident memory $\mathrm{T}\left(\mathrm{T}_{\mathrm{RM}}\right)$ cells in antitumor immunity: A unique functional contribution of the CD103 integrin. Front Immunol 9: 1904, 2018.

41. O'Donnell JS, Massi D, Teng MWL and Mandala M: PI3KAKT-mTOR inhibition in cancer immunotherapy, redux. Semin Cancer Biol 48: 91-103, 2018.

42. Dunai C and Murphy WJ: NK cells for PD-1/PD-L1 blockade immunotherapy: Pinning down the NK cell. J Clin Invest 128: 4251-4253, 2018

43. Liu Y, Cheng Y, Xu Y, Wang Z, Du X, Li C, Peng J, Gao L, Liang $\mathrm{X}$ and Ma C: Increased expression of programmed cell death protein 1 on NK cells inhibits NK-cell-mediatedanti-tumor function and indicates poor prognosis in digestive cancers. Oncogene 36: 6143-6153, 2017.

44. Brand A, Singer K, Koehl GE, Kolitzus M, Schoenhammer G, Thiel A, Matos C, Bruss C, Klobuch S, Peter K, et al: LDHAassociated lactic acid production blunts tumor immunosurveillance by T and NK cells. Cell Metab 24: 657-671, 2016.

45. Coca S, Perez-Piqueras J, Martinez D, Colmenarejo A, Saez MA, Vallejo C, Martos JA and Moreno M: The prognostic significance of intratumoral natural killer cells in patients with colorectal carcinoma. Cancer 79: 2320-2328, 1997.

46. Imai K, Matsuyama S, Miyake S, Suga K and Nakachi K: Natural cytotoxic activity of peripheral-blood lymphocytes and cancer incidence: An 11-year follow-up study of a general population. Lancet 356: 1795-1799, 2000. 